\title{
A Química no Museu de Ciência
}

\section{Algusto Jorge Pereira Magalhäes*}

0 ano kctivo 1999/2000, inicinu-se; no Museu ds Ciência da Unitersidadé de Lishoa, conı algumas alterà қ̧̌̉es Łุue rapidantente se tomaranı perceptiveis ạ público.

Após a conclusão das suas novas instalaçues. nus campus da Cidade Universitária, o Departamento de Quí mica e Bivquimica da Faculdade de Ciencias desocupou os laboratórios de química do edilício da Politécrica,

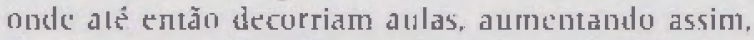
drasticancnte, a área disponivel no Museu de Cićncia.

Estes novos espaços, quer pela sua estrutura imaioritariamente taboratórios). quer pela sia anterior utiliza * çãu, constituem áreas privilegiadas para a montagen kt* exposiç̃ês relationadas com a Química, ramo da cienncia quc apenas se cnconirava representado no Museu de Ciência pela exposiçāo provisória de equipancento histórico "Um Breve Olhar Solire a Quimita...". exclusiva. mente contemplativa.

Uı1 dos espaços recém integrados, u antigo Lahoratório de Quiluica Inorgánica, apresenta. tielas suas dimensūes. esırutura e locali»açăo com acesso directo para o exterior do edificio, as caractcristicas ideais para a montagem de um espaço experimestal na árça da qquimica, dirigido prelerercialmente a pequenos grupos de alunos dos Ensinos Básitu e Serundário.

Pretcrde-se que este espaçu constitua um agradável ponto de cuntacto som a experinn:ntação sm quínica. procurandu-se quc os visitantes. cm constante intcracçàu com a monilor da expusiçăo c' com os materiais expostos. reconheçam que a química é tura ciência:
a) agradável de estudar:
b) cum inúmeras pontes cono o quotidiano:
c) cum uma história,
d) com futuro.

Para sluc estes objectivos sejam atingidos, foi criado um conjutllo de exj»riências muilo simples, benc conno os respectivos materiais de apoio, sendo os visitanles convidados a manusear on materiais, realizar as expcriencincias $t$ regislar os resullados. Ajois uni periodo de obras de recuperação do laboratório, loi montada a exposição, rescbendo este espaço us seus primeirus visitantes em Janeiro de 2000.

A componente histórica não foi esquecida, sendo referida no fnicio da visita, de forma muito breve, a história do laboratórto e sendo os visilantes convidados a tomar conlacto com nones e realizaçōes de cientistas iguímicosi) famosos.

Este novo serviço grestado au público pelo Museu du Ciência recebeu o nome de "Olitinas Experimenlais de Quinica - Vamos ao Latsoratório" e destina-se, por eлquanto e a título expetinental, apenas a grupos de alunos do 3" Ciç̄o do Erisino Básico. Pretende-se a curto prazo alargar o público alvo destas actividades a grupos de alunos do $8^{\circ}$ au $12^{\prime \prime}$ aлo e au puiblicu năo escolar.

Para site ano leclivo, foram momiados novos trabalhos sendo as oficinas divididas em tres pactes, de uma hora cada, a escolher pelo professor nu acto da marcaçào:

\section{CADA COR SEU... pH !}

Conjuno de cxperiências subre o tema ácido-base:

Vamos medir $\mathbf{p H}$ - Mediçăo do valur de $\mathrm{pH}$. com papul indicidor, de vinagre, limpa-vidros e kite.

Menxagens secretas - Constataçà̃o das corcs da lenul[taieina com sinagre e limpa-vidros.

Cores na cozinha - Exıração č teste do indicador de cuuve-roxa (antocianinas).

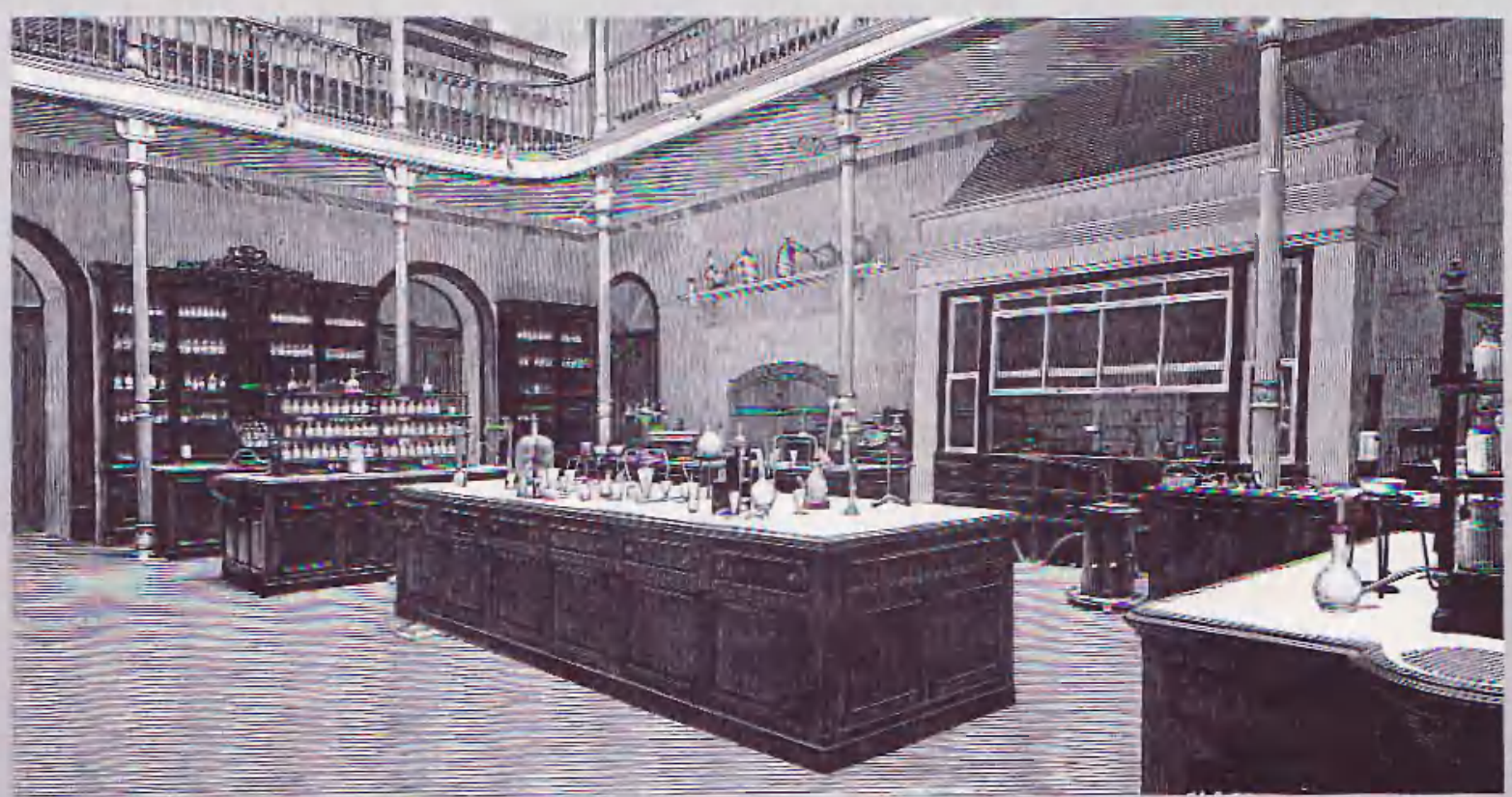

Vista geral do Laboratôrio Chimico. 
$a n \quad t \quad a \quad l \quad o \quad q \quad i \quad a$

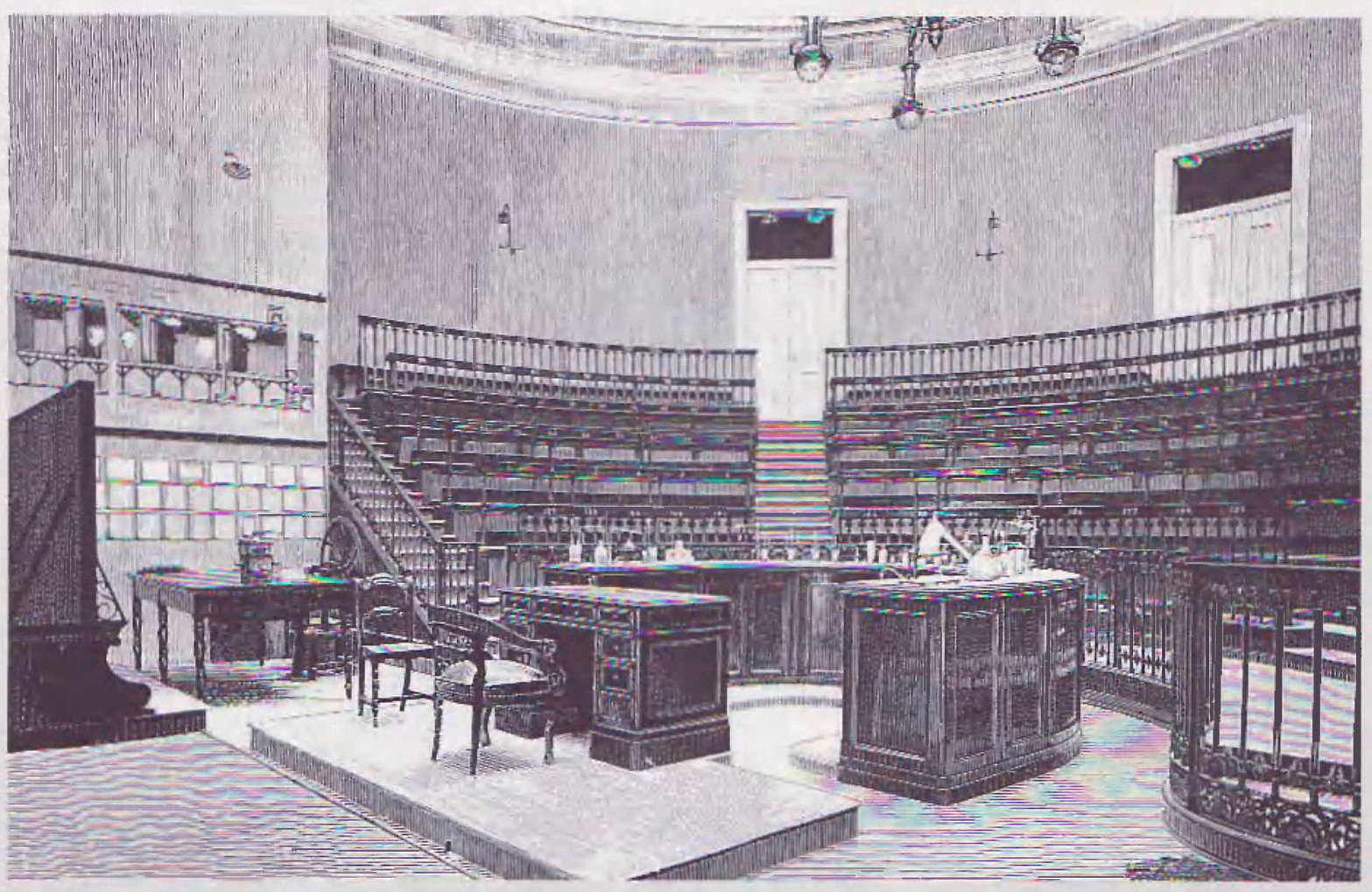

Amphitheatro Chimico ivista guralls.

Enchendo balōes - Rcalização de una reação ácido-basc com um produto gasoso.

\section{AS APARÊNCIAS ILUDEM...}

Conjunto de experiencias sobre o tema misturas c separaşüo dus scus cumponentes:

Será mesmo preto? - Cromatogralía en papel de un conjunto de tintas.

Agarrar sem locar - Scparação magnética de una mistura de limalha de ferro com arcia.

Tirar água da lama? - Fithraçỡo de una mistura.

O chá das cinco (demunstraçầu - Extraç̧ăo súli(o)-liquido itilizando um aparelho de extracção contínua de Sultxlet.

$56 \mathrm{H}_{2} \mathrm{O}$ (dimonstraçăo) - Destilação de ágta.

\section{UM TOQUE DE QUIMICA} dus:

Conjuntu de expertências sobre temas diversifica-

O detective sou eu - Revelaçău de impressürs digitais por sublimaçàu de iodo.

O banho de Sol - Vistialização da proteç̧ão de um creme solar utilizando luz ulıravioleta.

Cores na cozinha - Extracção e testc do indicador de colive-roxa (antocianinas\}.

Será mesmo preto? - Cromalugralia em papei de un conjunto de tintas.

O chá das cinco idemonstraçăo - Exiraçào sóli- do*líquido utilizando um aparelho de exeraç̧āo comıinua de: schloxles.

Estas Oficinas de Quimica cricontram-sc enquadradas num projecto mais amplo, no àmbito de um protucolo assinado entre o Muscu de Ciẻncia e o Ministcíno da Edıcaçàn, de que constam ainda "Oticinas Pedagogi. cas de Fisita - Un Toque de Fisica", "Oficinas Pedagógicas de Ambientc - Eu c a Terra" e "Oficinas Podagoujcas de Astrunumia - Astronomia de Dian.

Pensando na urganização da visita e de torma a quL' 0s atunos tirem o máximo proveito da mesma, estas Oficinas funcionarn sempre em jares d: molo a que uma turma possa estar ocupada na sta tutalidade. Assim. às tuartas-feiras luncionam as Oficinas de Ambi. ente e de Astrotomia ca quintas e sextas-leiras as th Química e de Física.

As oficinas podem ainda ser complementadas com ı́isitas à Exposiçăo Interactiva de Física, sessōes de Planetário e Visilas Guiadas do Laboratorio Chimico da Escola Pulitécnica.

Encuntrará lodas as inlormaçòes sothre esıas c outras actividades do Museu de Ciência em latıp://www.nzuseu-de-ciencia.ul.pt

Para marcaçōes de visitas ou quaisquer infurmaçōes contacie-nos: relefone 21392 is 08 - fax 213909326 e-I1 ail jnasa@museu-de-ciencia.ul.pt

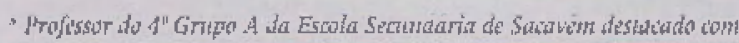

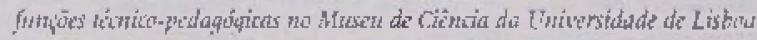

